\title{
Supporting Digital Supply Chains by IoT Frameworks: Collaboration, Control, Combination
}

\author{
Dániel Kozma and Pál Varga
}

\begin{abstract}
The purpose of this paper is to introduce a technology-oriented SCM (Supply Chain Management) development methodology, which can be used in the design of IoT (Internet of Things) frameworks especially characterized by supply chain processes. In order to meet DSC (Digital Supply Chain) expectations, two areas are examined in detail during the literature review. Firstly, the current SCM models are studied. Secondly, Industry 4.0 requirements had to be surveyed. As a consequence, challenges and gaps are identified for which we seek the solution during our research. Based on the results, it can be stated that digitization has definitely required an improved technological solution that IoT frameworks can provide. The result is a technology-driven, IoT-based SCM development methodology that serves as a basis for the design of such platforms, which will manage supply chains. To prove the feasibility of the proposed development methodology, the Arrowhead industrial IoT framework is used for validation.
\end{abstract}

Index Terms-Industry 4.0, Supply Chain Management, Digital Supply Chains, Productive 4.0, Arrowhead, IoT Systems, Development Methodology

\section{INTRODUCTION}

The processes of digitization and automation are setting a stronger pace than ever before, and they have a significant effect on the dynamic development of the industrial domain. The fourth industrial revolution - so-called Industry 4.0 [1] also poses challenges for organizational reformation, and it has a significant impact on corporate and production processes. The goal is nothing else but to increase productivity and efficiency - the organizations would like to produce more with their currently available resources - which is challenging to reach without significant investments. Taking into account the growing expectations for modern supply chains, there is a clear need for technological innovation in which IoT (Internet of Things) systems can help the supply chains to adapt to new circumstances, and ultimately to transform the original supply chain into DSC (Digital Supply Chain) [2]. However, a methodology specifically for this purpose has not yet been developed. In order to define the suitable solution, it is necessary to get to know the current SCM (Supply Chain Management) processes and used models, taking into account the Industry 4.0 expectations and - based on the results - to examine what technological processes, tools, and systems can be used to provide with the right result. Matching

Dept. of Telecommunications and Media Informatics, Budapest University of Technology and Economics, Budapest, Hungary

E-mail: \{kozma,pvarga\}@tmit.bme.hu) the SCM models with the expectations of Industry 4.0, as a consequence, the gaps become visible. Supplementing the knowledge gained during a thorough literature review with empirical results, the paper's novelty strives:

1) to cover the described technology-related SCM gaps;

2) to propose a technology-driven, IoT-based SCM (hereafter IoT-SCM) framework development methodology specifically targeting the IoT domain.

The validation of the proposed IoT-SCM framework development methodology is also presented on a real industrial IoT framework, Arrowhead. Based on the results, the rule-set of the proposed IoT-SCM methodology can be used to create and manage supply chains with the help of IoT systems.

The rest of the paper is organized as follows. Section II reviews the literature on the SCM and Industry 4.0 fields; Section III examines the current challenges and research gaps of DSCs. As the main contribution, Section IV covers the identified gaps by introducing an IoT-SCM framework and platform development methodology, which is validated in Section V, using the Arrowhead framework. Section VI concludes the paper.

\section{LITERATURE REVIEW}

Supply chains are expected to be digitized over several iterations. Initially, it is easier to digitize technology-based processes such as production or logistics; however, there are parts, e.g., tendering, contracting, and other financial decisions, which will certainly be even human-driven for a while, and these areas will be suitable to rely more and more on technology and automated solutions in a later phase. Consequently, implementing the Industry 4.0 requirements is already having a big impact on the production and logistics, which leads to the management of a smart, efficiency-oriented, and value-driven supply chain.

To understand the motivation behind this technological change, it is necessary to examine how traditional supply chains are structured and function; furthermore, align this operation with Industry 4.0 expectations. This can reveal how the traditional, manual, mainly human-operated supply chains can transform into DSCs.

\section{A. Managing Supply Chains}

Basically two cross-functional, cross-firm and process-based SCM approaches exist: the SCM Framework [3], [4] and the SCOR (Supply Chain Operations Reference) [5], [6] model. 
1) The SCM Framework: In this terminology, the main focus is on relationship management, which is broad in its scope, including activities such as product development, demand generation, relationship management, and returns avoidance. This breadth is why the participation of all the functional areas is critical in the SCM Framework. The model defines eight processes that touch all aspects of managing the business. Each process team is comprised of managers from all business functions, including marketing, sales, finance, production, purchasing, logistics, research, and development, as Fig. 1 shows.

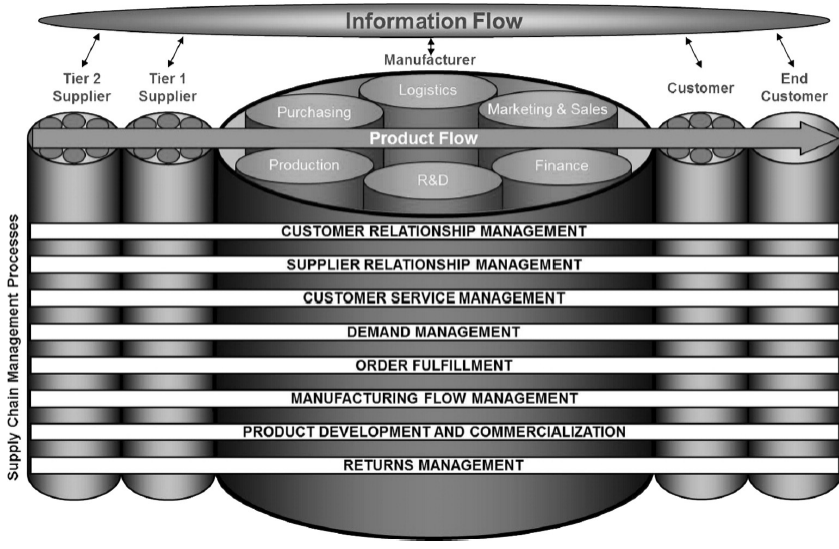

Fig. 1: SCM Framework [4]

2) The SCOR model: It is a process model of an industryindependent approach for supply chains. The model enables SCM methods to be shared and co-developed in the supply chain according to the parties' needs. The SCOR can be recognized as a reference model that can be used as a starting point for supply chain planning or development across the border of different companies. It can be used as an analysis and optimization tool for identifying the weaknesses of existing models. SCOR provides three-levels of process detail and optionally another one for company-specific considerations. At this level, the model provides an opportunity that companies define practices and individual SCM methods to attain competitive benefits and adjust to changing business conditions, as Fig. 2 shows. The SCOR model visions four main fields along with the proper SCM can be realized:

- Processes: Standard descriptions of management processes and process relationships;

- Performance: Standard metrics to describe process performance and define strategic goals;

- Practices: Management practices that produce significantly better process performance;

- People: Standard definitions for skills required to perform supply chain processes.

3) Comparison of the approaches: Based on a thorough review [4], the SCM Framework and SCOR are similar because both of them support cross-functional involvement and also realize that company functions cannot be replaced by business processes. However, the number of functions included in each framework is different, and the type of cross-functional involvement differs. In the case of SCOR, the cross-functional

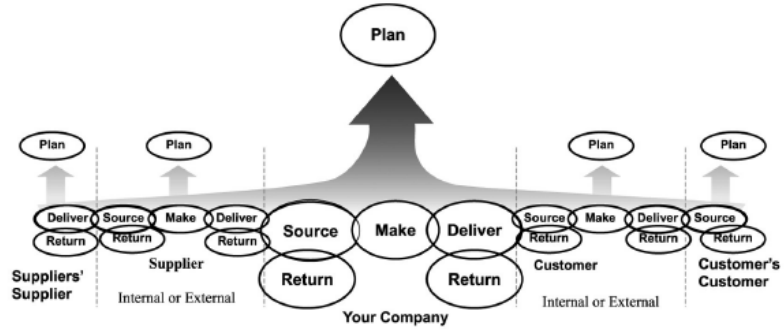

Fig. 2: SCOR model [6]

involvement is pursued primarily within three functions: logistics, production, and purchasing. While SCOR includes enabling as a process, the activities included resembling the SCM Framework's management components. Focusing on just three functions might make SCOR easier to implement, but this means that other areas that affect the supply chain such as research and development, marketing, or finance will be less emphasized - which, in contrast, are addressed by the SCM Framework.

\section{B. The Revolution of Industry}

Changes in the industry affect not only manufacturers but also those processes that support production. Based on the literature [1], [7], the definition of Industry 4.0 can be summarized as a general terminology and concept for the fullydigitized production. In the modular Smart Factories of Industry 4.0, various Cyber-Physical System (CPS) processes can be monitored through virtual mapping and decentralized realprocess decisions. Real-time communication and collaboration can take place between people and machines or between either of them. With the support of the IoT domain, internal and external organizational services can be provided and accessed. According to the terminology, the general requirements of Industry 4.0 are focused on the following terms.

1) Interoperability: In the Smart Factory concept, all CPSs within the factory can communicate with each other through a well-defined interface - from the workpiece carriers, through the assembly stations to the handling of products. This means the interconnection and collaboration of different machines, vehicles, equipment, and people through IoT.

2) Virtualization: The virtual mapping of the factory means that CPSs are monitored based on real-time data coming from different sensors. The data extracted from the sensors are linked to the factory's virtual model and various simulation models, whereby the physical world can be mapped and represented virtually. For a factory, the virtual model includes the status of all CPSs what helps the operators to react to different, unexpected events instantly.

3) Decentralization: The demand for individual products is increasing, and defining the core manufacturing processes is getting more and more difficult. The CPS approach allows making independent decisions in certain situations where intervention is required from a higher entity than the physical system itself, such as in cases of failures or unexpected events. In predefined manufacturing, services provided by machines can identify production workflows. Therefore, instead of fully centralized and controlled production, decentralized produc- 
Supporting Digital Supply Chains by IoT

Frameworks: Collaboration, Control, Combination tion can occur, which requires a well-defined production framework.

4) Real-Time Capability: This is required since operations have been drastically accelerated in various segments of our world - including industrial production and logistics. To support different organizational processes, it is essential to collect and analyze data in real-time. Industry 4.0-capable systems can continuously monitor and examine the state of the plants and the production. Thus, if a problem arises during production, the factory can respond in real-time and redirect the manufacturing process to another internal workstation or even another external factory.

5) Service Orientation: Another crucial factor concerning the feasibility of IoT and Industry 4.0 is the approach of SOA (Service-Oriented Architecture) [8]. Services provided by companies, CPSs, and people are available over digitized infrastructures and can be used by other participants or offered inside and outside the company. As a result, product-specific operations can be implemented, e.g., by the RFID tag, and can be adapted to customer-specific requirements, independently from factories.

6) Modularity: This term suggests that a system can flexibly adapt to the changes of the modular palette in case of swapping, removing, or expanding modules (or systems). In Industry 4.0, based on standard software and hardware interfaces, new modules can be automatically identified and used immediately.

\section{SuRVEy on the Challenges of Digital Supply CHAINS}

The emphasis of the DSC is not on whether raw materials, goods, products or services are digital or not; the point is that the management of supply chain processes will be digitized, using new technologies such as crewless vehicles and cloud computing, among others [2]. The more stakeholders who use digital solutions, the easier it is to drive information transparency, track goods, and optimize. As the supply chain becomes more distributed, digital transformation and stakeholder integration in a common SCM platform can bring benefits. Combining this with emerging SCM-related technologies, great opportunities can be provided for businesses to understand the supply chain better, reduce costs, and increase the speed, quality, and flow of goods.

The increase in same and next-day delivery has created a level of demand that puts new pressure on businesses. As demand grows, the entire supply chain evolves rapidly from a functional orientation to global and interconnected networks. There are many new and emerging ways for companies to reshape their supply chain to meet the needs of modern customers. Advanced technologies such as artificial intelligence (AI) [9], blockchain [10], and in general, automation [11] are being integrated into the DSCs, integrating data and any other resources from different locations to drive the distribution of manufactured goods along the value chain.

Of the two SCM models introduced earlier, the SCM Framework is complete in the sense that it also covers management processes, while the SCOR is much more concerned with logistics, production, and purchasing. However, as has been emphasized before, certain decisions cannot be brought fully automatically, such as tendering, contracting, and other financial decisions, where the human factor still plays a major role due to specific agreements and bargains. Nevertheless, the SCOR approach's scope aims to cover exactly those areas (logistics and production) in more detail, which can be automated on the technological levels. It should be noted that with the help of smart contracts [12], purchasing has already moved in the automated direction, but here the human factor is still significant.

Considering the scope, we analyze SCM's challenges according to the SCOR approach - due to its more technical nature. Therefore, the following subsections will review the challenges from the SCOR-defined fields, i.e., process-, performance-, practice- and people-related points of view.

\section{A. Process-related challenges}

1) Market growth: The cost of production is significant from research through development to product introduction. Therefore, the primary purpose of companies is to expand the emerging markets and to increase profits. Access to new market areas is difficult, especially when it comes to foreign countries, as trading policies, different fees, and government regulations may vary. The number of suppliers is also expanding. In this ever-expanding market, it is also challenging [13] to plan the supply chain in the beginning. The challenge is to find the appropriate supplier with the proper solution. Another challenging factor is reaching new customers. A further result of market growth, the efficiency of the supply chain is even more dependent on the proper tracking, authenticating the sending, receiving, and location of goods, which is a big challenge. The lack of these can lead to unnecessary delays and holdups, damaging the operations throughout the supply chain. Periodic evaluations and redesigns are required to be efficient and effective as possible. These adjustments respond to market changes - changes such as the introduction of new products, global sourcing, the availability of credit, and the need to protect intellectual property. These risks need to be identified and quantified to allow for control and mitigation.

2) Individual needs: The modern supply chains are complex. If we add products that are continually changing, the challenge is even higher [14]. The customers are putting continued pressure on companies for newer innovations, which allow them to stay competitive. In order to improve the products, companies need to transform their supply network. To respond to market needs, companies should adapt the production flow according to the needs of customers and grant a broader scope of activities, which in most cases, involves modifying the established processes. The time for introducing new products - and thus the time for manufacturing itself is decreasing. This is an increasing challenge for manufacturers, as high-quality products must continue to be guaranteed in lesser time. While expanding the product range, there is another pressure on manufacturers to produce high-quality products that are secure and safe. Untrustworthy or defective products can ruin the company's reputation, which can only be slowly, but in most cases, never fully recovered. 
3) Globalization: Reducing costs is one of the biggest challenges for organizations. Therefore, to reduce the price, companies have moved to manufacture in countries where production costs are lower. However, customers want to get their products not only cheap but in time. Although production will be cheaper this way, cross-border transportation is needed, which can lead to delays; even a small decline in supply chain efficiency can have a significant impact on productivity and profitability. Without accurate status reports, supply chains can lose resources and time, making it more difficult to meet with the preplanned goals. In order to support globalisation [15], there is a need for an effective global procurement network that is capable of fully supporting the supply chain and responding to its needs in time. The careful selection of a strategic supplier is also outstanding. It can ensure the appropriate manufacturing locations and various production-supporting services on high quality. Consequently, in the globalization of manufacturing operations is important to have a global supply chain network that can effectively support and quasi in realtime response to the needs of the supply chain.

\section{B. Performance-related challenges}

1) Analytics of supply chain: According to the requirement of supply chains to be adaptable and react quickly to unexpected events or changed needs, real-time processing of data generated in the supply network is essential. Collecting the growing amount of supply chain data is not really a problem, but its effective analysis is [16].

2) Cost-control: Operating costs are under immense pressure from rapid changes in various factors such as rising material and energy prices, fuel and freight costs, fast technological changes, new regulations, and more global customers [17].

\section{Practise-related challenges}

1) Lack of Transparency: Traditional supply chains are often non-transparent and complex to understand. This makes it difficult to track and plan how goods and resources move through the supply chain [18]. Without complete transparency the optimization and efficient management are nearly impossible. This problem is exacerbated by older software and system solutions that do not allow information to be collected, managed, and transmitted efficiently.

2) Trusted resource exchange: Without trust, resources and information cannot be shared, and thus supply chain managed effectively. With the spread of digitization, there is an increasing need to rely on technological solutions, which poses new risks. A well-designed system provides plannable and predictable results as well as better supplier and partner relationships [19].

\section{People-related challenges}

1) Stakeholder integration: The consolidation of stakeholders can bring many advantages, and it can eliminate supply base variances and overheads [20], among others. Here, the challenge is to find a supplier who has the most efficient solution for the given problem. However, supply chains need to be as fast as possible to meet the demands of modern consumers. A complex, legacy supply chain often relies on the goodwill and established norms to work well. When these areas are challenged by increased demand or external disruption, relationships can suffer, together with the quality and timeliness of supplying products. It is a must to create, understand, and follow commonly agreed standards to better understand current performance and opportunities for improvement. This is an area that can become automated in a wellcontrolled and planned environment.

2) Governance and regulation-related challenges: A big challenge in the implementation of DSCs is to involve the massive and growing volumes of data produced today, and the tension between protecting internal data while still sharing product and consumer information with partners across distributed supply chains [21]. This is especially true for personal and sensitive personal data. For their protection, multigovernment regulations have been established, and one of the best known of them is the GDPR (General Data Protection Regulation) [22]. The goal of GDPR is to protect the privacy of EU citizens expressly. While many firms believe that GDPR does not affect them because they are outside of Europe or do not directly handle customer data, in most cases, this is not true. Supply chains often cross borders and continents. Therefore, it is very important to ensure legal-compliance within these supply chains in all cases. As a result, companies must take special care when transmitting customers' or even suppliers' personal data. Besides, it can be stated that noncompliance with the regulations can lead to a huge, and in some cases, fatal monetary loss. Following the example of GDPR, damages for non-compliance could amount to $€ 20$ million or a maximum of $4 \%$ annual worldwide turnover [22].

\section{E. Research gaps related to digital supply chains}

Based on the previously-presented challenges and taking into account a comprehensive, supply chain-related research presented by [2]; the following subsections will address the current gaps.

1) Lack of development frameworks: Very incomplete, quasi no methodology is provided for digital SCM. These principles would help managers and developers to build, deploy, and use digital platforms specifically designed for DSC-related processes.

2) Lack of technology: DSCs are different from the currently widespread supply chains. Decisions in the DSC-context require new tools and technologies that take into account the digitization environment. DSC will affect maintenance, quality, inventory management, logistics, production planning, and procurement, among other issues, where there must be a system capable of bringing intelligent decisions; analyzing big data; transferring information and resource in an automated way; modeling digital twin; maintaining cybersecurity, and provide with modularity and flexibility [23].

3) Lack of integration: There are numerous barriers to the rapid implementation of DSC from both managerial and technological perspectives. Organizations are at the edge of competition to transform their supply chains digitally. Thus, 
Supporting Digital Supply Chains by loT

Frameworks: Collaboration, Control, Combination

technology-related expectations addressed in the previous subsections need to be resolved and implemented; furthermore, integrated in real-time. There are only a few studies on how to deal effectively with the transition from traditional supply chains to DSCs.

In the next section, a methodology will be introduced in line with the gaps that can help build DSC-compliant IoT platforms. The proposed methodology takes into account the main technological areas and also addresses integration issues.

\section{SCM-SPECIFIC DESIGN METhOdology FOR IoT FRAMEWORKS}

Based on the challenges presented in the previous sections, there is a clear need for a standard or guidance with which those needs can be served. Although many gaps have been identified in many articles, there is still no precise technical recommendation specifically describing how DSC could be supported. However, the presented gaps provide great help to define the exact requirements. The following subsections present the main pillars of our proposal on which the technical solution can be based. In some cases, there were already recommendations in the literature; still, they no longer fully meet the new requirements. Therefore, in addition to the novelties, we also supplemented the previously defined terminologies and processes, making them Industry 4.0 and DSC compliant.

\section{A. Basic architecture}

According to Sampson and Froehle [24], the basics of manufacturing supply chains are very similar to each other. As Fig. 3 shows, the traditional supply chain was a one-way, unidirectional chain where consumers may have an impact on product design, but they are mostly out of the production.

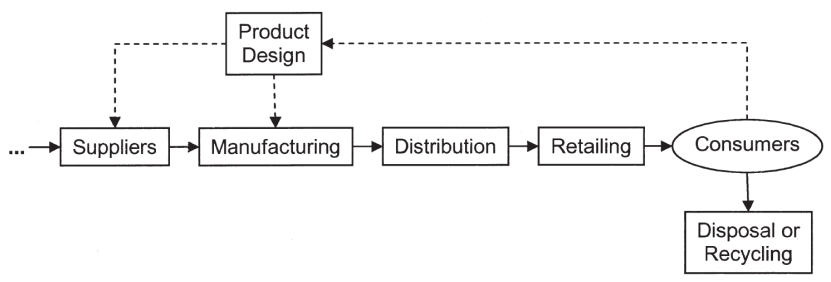

Fig. 3: Unidirectional supply chain - Traditional approach [24]

As mentioned in the challenges, on the one hand, nowadays, it is becoming increasingly crucial for the modern consumer to get individual products. On the other hand, the shortness of time from order to delivery is an increasingly critical factor. Traditional supply chains cannot serve this expectation. Here came the realization that the unidirectional chain needs to be made bidirectional. In response to this gap, the UST (Unified Services Theory) [24], [25] came alive, where the supply chain consumers have an expanded role; thus, the traditional oneway chains become bidirectional. This approach divides the supply chain roles into two major groups of stakeholders, and it led to the service provider-consumer model, as shown in Figure 4.

Based on the model, the provider can be a supplier for any resource or service requested by the consumer. This approach

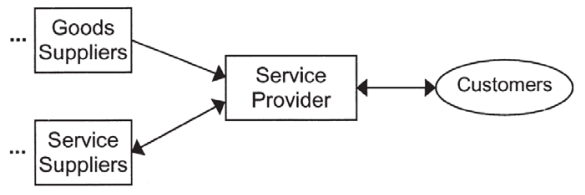

Fig. 4: Bidirectional supply chain - Modern approach [24]

is the same as the service-oriented expectation advocated by Industry 4.0; therefore, the architecture for IoT-SCM design will be SOA; thus, at the same time, the bidirectional supply chain concept and the Industry 4.0 expectation are met.

In relation to SCM, three major dimensions have been identified following the literature review where the supply chains can be supported on technology level: Collaboration [26]-[28]; Combination (and integration) [29]-[31]; and Control [32][34]. In the following, the main activities will be introduced; besides, their further sub-activities will be defined.

The concept of CCC (Combination, Collaboration, Control) [35] can be seen in Figure 5. This model summarizes the technological requirements for developing a DSC-compliant IoT-SCM system.

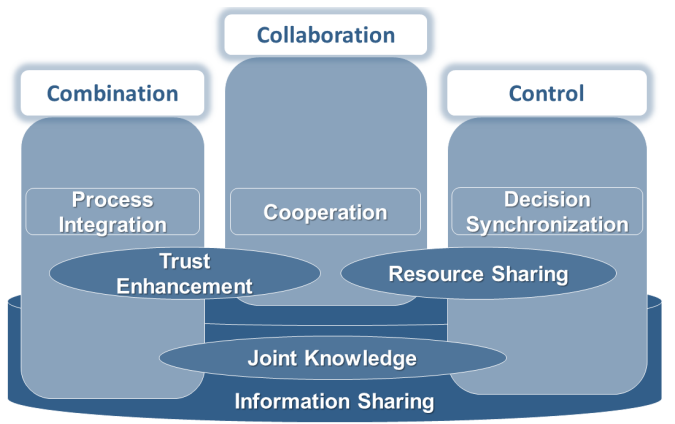

Fig. 5: Combination, Collaboration, Control

\section{B. Collaboration - a main activity}

Based on the presented research [26]-[28] and experimental results, it can be stated that it is one of the most important pillars within the supply chain in achieving effective production.

Collaboration ensures communication between participants of the supply chain and allows for the human-CPS partnership. Logistics processes, stakeholders, and production management require a well designed SCM [36]-[38]. Developing the supply chain network is always project and domain-specific, but the foundations are still similar. In this activity, the focus is on the relationships between suppliers and manufacturers, companies, and manufacturers, and last but not least, between companies and consumers, where there is a provider-consumer relationship between everyone. In order to create an effective collaboration, it is necessary to make cooperation technologically available. The verb cooperation is often used as a synonym for collaboration, but there is a significant difference between them. The target is the same, but the approach is not. Cooperation means that every participant is working to achieve the primary goal together with their own benefits; in this 
aspect, the collaboration combines cooperative activities for a greater purpose. Another important aspect of the collaboration is that the partners equitably distribute the risks, costs, and rewards of the production within the chain [39]. To aim this, frequent, balanced, bidirectional, and multilevel information sharing is needed that indicates a close relationship between the partners [40].

Furthermore, during collaboration, it is necessary to share not only information but physical resources as well; however, the information and resource sharing are impossible without trust. Trust is the foundation of every high-performance supply chain, and transparency is a critical element of building trust between members of the chain [41]. Trust helps contact between the participants, resulting in long-term collaboration and greater benefits. However, trust also includes providing proper security for communication, data, and different artifacts created by the chain. Based on these, the Collaboration main activity can be divided into four sub-activities, i.e., cooperation, information sharing, resource sharing, and trust enhancement.

\section{Combination - a main activity}

The term "combination" in this context refers to the integration of several continuous or similar, independently executed processes, or any kind of resources [29]-[31], and it places more emphasis on central planning, ownership, which is governed by contractions.

The combination of supply chain processes means that the company and its partners work in sync, based on common terminology and standards, to achieve the specified business goals through integrated business processes and information sharing. To accomplish this, global processes must be inserted into the supply chain [42]; furthermore, all supply chain members must apply the same principles, standards, and procedures to reduce the risks and improve the interaction between supply chain partners and corporate strategy [4]. In this case, of course, it is also necessary to ensure trust as well. The chain members need to know that they can trust each other in every circumstance, knowing that while doing everything they do, the rest of the chain will act similarly.

Besides, processes in the supply chain must be continuously monitored and optimized. This activity will provide the participants with a better understanding of the market and the competitive environment. This will result in a joint knowledge [43], which can help future production thanks to the continuously shared information and documented experiences. Based on these, the Combination main activity can be divided into four sub-activities, i.e., process integration, joint knowledge, trust enhancement, and information sharing.

\section{Control - a main activity}

In the past, "coordination" was the term used conceptually [44]-[46], but according to the changes and the presented expectations, now the coordination in itself has not been proven expressive enough. It is an essential part of SCM but can be subject to a more significant term, the Control [32] [34]. The participants and the processes need to be coordinated and controlled from managing inventories through production management or different quality management to plan and implement considerations.

In this aspect, it can be stated that the synchronization of decision-making [47] is an important control-related task. The decision synchronization is a must between participants in a DSC; the common design, implementation, or processrelated questions have to be clarified. Furthermore, market decisions such as pricing, decisions about various product features, or the optimal order quantity regarding materials or products are decision-based factors as well. Nevertheless, it also has a critical issue that not everyone has the right to make decisions at all levels, which is leading to conflicts. To avoid this situation, a transparent framework, clear roles, and coordination are needed [48].

Continuing this line of reasoning, the flow of information must also be directed and controlled. It is important that participants have access to information based on privileges and that unauthorized people do not have access to business secrets. The establishment and maintenance of information security [49]-[52] is an essential condition for next-generation systems, partly because they make it easier to comply with legal rules such as GDPR. It follows from the management of information sharing that the knowledge achieved during the management of supply chain processes cannot be made available to unauthorized people either. This kind of knowledge usually provides a competitive advantage to the actors in a given supply chain over the competition.

In DSCs, resource sharing becomes dynamic, in some cases fully automated; for example, on the production level, robots are automatically allocated to production lines, or even a production process is dynamically taken over by another factory. Based on these, the Control main activity can be divided into four sub-activities, i.e., decision synchronization, information sharing, resource sharing, and joint knowledge.

\section{E. System classification}

Based on the CCC model defined in the previous sections, it is possible to classify the planned IoT-SCM system's subsystems. According to the sub-activities described in the CCC model, it is possible to determine what activities a subsystem is involved in, and the importance of the system can be determined accordingly. In the CCC, seven sub-activities are identified.

1) Grade I.: If a subsystem is involved in a minimum of six out of seven sub-activities of CCC, it will certainly be an indispensable subsystem from the entire system point of view. All stakeholders need to implement and use it; therefore, it can be considered as a mandatory subsystem, in this terminology, a Grade I. system.

2) Grade II.: If a system is involved in three to five subactivities of CCC, then it can be considered as a less important subsystem, which is necessary for a specific actor, or actors of the supply chain, but not globally obligatory from the whole supply chain point of view. Without them, the supply chain can now work together, but perhaps not as effectively; therefore, it can be considered as a supporting subsystem, in this terminology, a Grade II. system. 
Supporting Digital Supply Chains by loT

Frameworks: Collaboration, Control, Combination
TABLE I: System classification

\begin{tabular}{|l|l|}
\hline $\begin{array}{l}\text { Sub activities } \\
\text { [number] }\end{array}$ & Grade classification \\
\hline $6-7$ & Grade I. \\
\hline $3-5$ & Grade II. \\
\hline $1-2$ & Grade III. \\
\hline
\end{tabular}

3) Grade III.: If a system is involved in one to two subactivities of the CCC model, then that system is specifically important to only one actor, mostly some kind of local system or application that is solely responsible for a particular subactivity. From a global perspective, it is among the least dependable subsystems, in this terminology, a Grade III. system.

According to the classification method, the Table I summarizes the suggested Grades in relation to the sub-activity numbers. Naturally, it can depend on individual decisions of the given context, from which it follows that the borders may change.

This kind of classification is important because, on the one hand, the cross-operation within the supply chain requires that actors use the same platform where it is a must to know what systems are required to enable participants to communicate and collaborate. On the other hand, reacting to the new trends, new subsystems will be developed to meet changing expectations. This classification technique also helps to classify and integrate new systems into the existing ecosystem, with the appropriate weighting.

\section{F. Lifecycle management and toolchains}

The modular approach of Industry 4.0 requires systems to be integrated into industrial systems (e.g., CPS) as efficiently and quickly as possible. This requires - among others up-to-date knowledge of the system states and the actions needed at state transitions, and its success depends on the consistent development and management of systems through their lifecycle. Whereas systems in the industrial ecosystem are constantly changing, new ones are integrated, old ones are taken out; therefore, these actions must dynamically take place, along with preplanned processes [53]. To this end, for the IoT-SCM framework, a lifecycle model should also be defined to support these procedures, as well as a toolchain in line with the lifecycle model. Therefore, all supply chain actors are aware of the need for such tools for the given IoTSCM system. Special care must be taken in the lifecycle and toolchain management [54], [55]:

- to meet the Industry 4.0 requirements;

- to accommodate standard modeling techniques;

- to provide a single framework for the design, implementation, integration, and management of systems;

- to maintain the hierarchical and modularity expectations;

- to provide tools for the agile and dynamic construction of systems;

- to enable the automatic deployment of systems;

- to enable interoperability and integrability for heterogeneous systems;

- to enable a service-oriented architecture guaranteeing adaptable, loosely coupled, and late-bound services; furthermore, which can be measured, evaluated, and can adjust to new trends and changes.

\section{VALIDATION OF THE IOT-SCM DEVELOPMENT METHODOLOGY}

The concept of the development methodology described in the previous sections needs to be validated on a minimum prototype implementation. For this purpose, the Arrowhead industrial IoT framework will be used. The Arrowhead [56] is an open-source project developed by ARTEMIS - Advanced Research and Technology for Embedded Intelligence Systems the European Technology Platform for Embedded Computing Systems. Now, Arrowhead has been further developed within ECSEL Productive 4.0, which is an ambitious holistic innovation project that aims to open up the opportunities for the Digital Industry.

\section{A. Basic Architecture of Arrowhead}

In line with Industry 4.0 expectations, Arrowhead is also based on the SOA. The framework envisions local automation clouds capable of performing both local and remote tasks, creating dynamic collaboration between different participants. Besides, according to the other requirements of Industry 4.0 (i.e., flexibility and modularity), it supports the collaboration of both legacy and newly built CPS architectures. Similar to the UST concept (see in Figure 4), Arrowhead separates service providers and consumers, as shown in Figure 6 , in line with SOA. The figure also shows the Arrowhead systems (detailed in the next subsection) that all participants must implement to use services from each other.

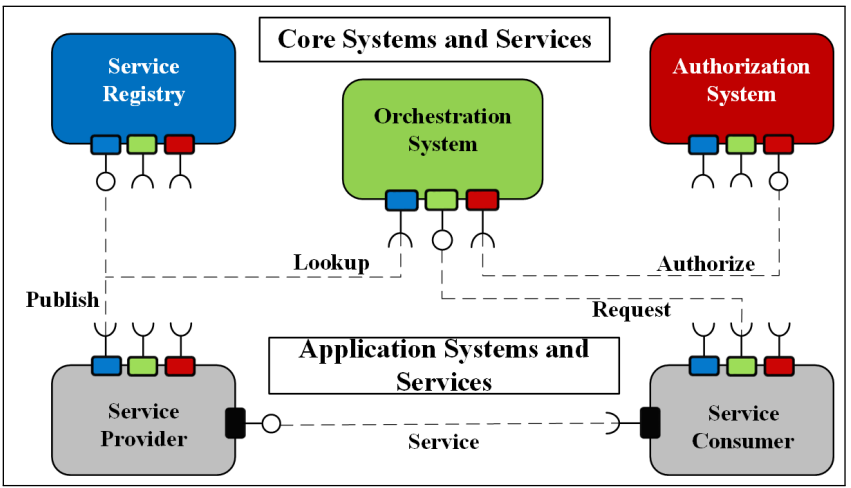

Fig. 6: Service-oriented approach of Arrowhead [56]

\section{B. Arrowhead Systems and Classification}

The current Arrowhead systems and their classification are illustrated in Figure 7. As shown in Figure 6, in order for the service-oriented operation to be realized, there are three mandatory, Grade I. systems.

1) Grade I. systems: In the Arrowhead terminology, these are the so-called Mandatory Core Systems, which includes the three basic pillars of the framework [56]:

- Orchestration System is a central component of Arrowhead. The process of orchestration is essential in support of service re-usability, service discoverability, and 
service composability. From an architectural perspective, the Orchestration System is responsible for finding and pairing service consumers and providers;

- Service Registry provides storage of all active services registered within a local cloud and enables the discovery of them for remote clouds too. A local cloud should contain only one Service Registry. Here are all three important elements of SOA that are fulfilled: loose coupling, late binding, and lookup;

- Authorization System provides Authentication, Authorisation, and optionally Accounting (AAA) of a system consuming a produced service.

2) Grade II. systems: In the Arrowhead terminology, these are the Supporting Systems, which help to create and operate SoS (System of Systems). The set of Supporting Systems is growing, as new ones appear according to current expectations. They are involved in managing more sub-activities defined in the CCC model. Such systems include QoS (Quality of Service) Manager [56], System Configuration Store [56], Gatekeeper System and Gateway [57], Event Handler [58], Plant Description System [59], Translator System [60], Historian [56] and Workflow Choreographer [54], [61].

3) Grade III. systems: Alternatively, in Arrowhead, these are the Local Cloud Specific Systems or Application Systems, which are part of a CPS with sensory and functional capabilities in the "real world". Arrowhead does not make any assumptions about what an Application System might be. It can be a single sensor or a whole, large smart environment. The emphasis here is rather on the fact that an Application System provides and consumes services from the other local cloud systems, and Mandatory Core Systems govern this information exchange. For the most part, they perform a single, specific sub-activity defined in the CCC model.

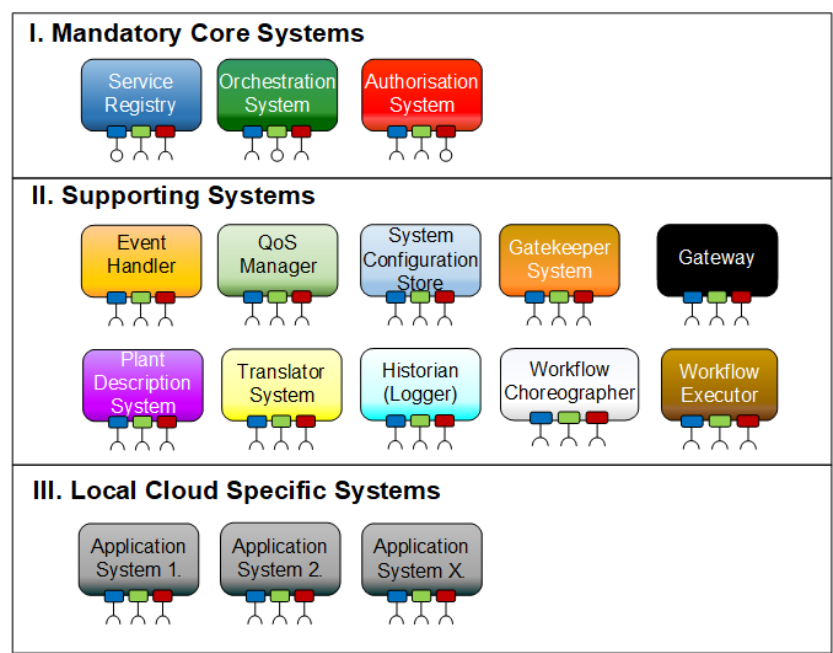

Fig. 7: System classification of Arrowhead for the given example [62]

\section{Examples for classification of Arrowhead systems}

In the following sections, an example is provided regarding the Arrowhead framework system-set: how to classify them to the presented Grades according to the proposed methodology. Table II summarizes the results of classification.

\section{Grade I. - Orchestration System}

This system provides the matchmaking within Arrowhead, basically participating in all sub-activities of the CCC models.

1) Information Sharing: An enabler through creating the connection between the service consumer and provider;

2) Resource Sharing: Enabling the consumer to connect the needed service resource and control the flow;

3) Decision Synchronization: Controlling the matchmaking process, often through information gathered from other Supporting Systems;

4) Joint Knowledge: Since the processes get to be transparent with coordination of the Orchestration System, the supply chain participants can get valuable knowledge about the current supply chain, its gaps, and how they can improve the supply chain processes;

5) Process Integration: With the usage of a common framework, the different processes of the supply chain participants will be integrated, which leads to everyone having the same understanding of the processes; therefore, the Orchestration System maintains the agreed processes;

6) Trust Enhancement: The service discovery is available between the remote and local cloud; therefore, the Orchestration System is also responsible for facilitating external communication over the Global Service Discovery mechanism;

7) Cooperation: Create the connection between the participants of the supply chain and control the cooperation.

\section{Grade II. - Workflow Choreographer}

This system manages workflows based on the production plan.

1) Information Sharing: It handles and provide useful, realtime information about the production;

2) Resource Sharing: The Workflow Choreographer controls the workflow in a distributed way. It instantiates the distributed Workflow Executors and allocates services to them based on the available resources;

3) Decision Synchronization: During the production, it manages distributed workflow execution and also brings smart decisions based on the unexpected events;

4) Joint Knowledge: After the workflow execution, useful knowledge can be gathered about the executed workflow, which opens the way for proactive maintenance and process optimization.

\section{Grade III. - Temperature Sensor}

The temperature sensor is located in a room of the factory.

1) Information Sharing: It provides information about its parameters such as temperature, general condition, location, among others.

\section{Lifecycle and toolchain management in Arrowhead}

As shown in Figure 7, the Arrowhead framework already has several systems - and the status of this ecosystem is constantly changing, where new systems will appear, old ones are restructured, or will be retired. Besides the expectation that all supply chain participants will work together using the 
Supporting Digital Supply Chains by IoT

Frameworks: Collaboration, Control, Combination
TABLE II: System classification of Arrowhead systems

\begin{tabular}{|l|c|c|c|}
\hline $\begin{array}{l}\text { CCC } \\
\text { Sub activities }\end{array}$ & $\begin{array}{l}\text { Orchestration } \\
\text { System }\end{array}$ & $\begin{array}{l}\text { Workflow } \\
\text { Choreographer }\end{array}$ & $\begin{array}{l}\text { Temperature } \\
\text { Sensor }\end{array}$ \\
\hline $\begin{array}{l}\text { Information } \\
\text { Sharing }\end{array}$ & $\mathrm{x}$ & $\mathrm{x}$ & $\mathrm{x}$ \\
\hline $\begin{array}{l}\text { Resource } \\
\text { Sharing }\end{array}$ & $\mathrm{x}$ & $\mathrm{x}$ & \\
\hline $\begin{array}{l}\text { Joint } \\
\text { knowledge }\end{array}$ & $\mathrm{x}$ & & \\
\hline $\begin{array}{l}\text { Trust } \\
\text { Enhancement }\end{array}$ & $\mathrm{x}$ & & \\
\hline Cooperation & $\mathrm{x}$ & $\mathrm{x}$ & \\
\hline $\begin{array}{l}\text { Decision } \\
\text { Synchronization }\end{array}$ & $\mathrm{x}$ & \multicolumn{2}{|}{} \\
\hline $\begin{array}{l}\text { Process } \\
\text { Integration }\end{array}$ & $\mathrm{x}$ & $\mathbf{4}$ & $\mathbf{1}$ \\
\hline Summary & $\mathbf{7}$ & II. & III. \\
\hline Grade & I. & \multicolumn{2}{|}{} \\
\hline
\end{tabular}

same processes and technological solutions, Arrowhead also allows participants to create their own Application Systems, which are then used locally or even be used by external actors. Accordingly, to make the development and integration dynamic, and even be accessible by external clouds, it is also necessary to determine the lifecycle of the systems and the tools used during the lifecycle. For this purpose, new lifecycle management [63], besides a new toolchain model [64] have been developed for Arrowhead. Although the trigger was to define models to the Arrowhead, these were universally designed to provide a good basis not only for the Arrowhead but for the SoS environments.

\section{CONCLUSION}

The novelty of this paper is to introduce a newly designed development methodology for IoT-based SCM frameworks and platforms. First, the related literature was reviewed to understand the motivation behind, examining the main SCM modeling approaches and changes brought by Industry 4.0. Based on the approaches and changes, the challenges and the gaps were identified. As a result, IoT-based frameworks and platforms have been identified to be a solution to support DSCs. Accordingly, a specific IoT-SCM development methodology has been developed, which defines these platforms' characteristics by three main activities, namely the Collaboration, Control and Combination, and their related sub-activities. Also, the SOA has been proposed as the basic architecture of the methodology. Besides, a classification technique of the systems is introduced as well, covering the requirements of modularity and flexibility, among others. The presented methodology has been validated by an existing industrial IoT framework, the Arrowhead. The introduced development methodology presented by this paper can serve as useful guidance for IoT-SCM system developers. The model covers the needs of Industry 4.0 and DSC as well. Industry 4.0 is still under standardization; therefore, the requirements could change in the future, just like the expectations of DSCs. On the one hand, the IoT-SCM development methodology must adapt to the changing industrial trends. On the other hand, the relevance of the presented methodology needs further and continuous review and fine-tune.

\section{REFERENCES}

[1] M. Hermann, T. Pentek, and B. Otto, "Design Principles for Industrie 4.0 Scenarios," in 2016 49th Hawaii International Conference on System Sciences (HICSS). IEEE, January 2016. [Online]. Available: DoI: $10.1109 /$ hicss.2016.488

[2] G. Büyüközkan and F. Göçer, "Digital Supply Chain: Literature review and a proposed framework for future research," Computers in Industry, vol. 97, pp. 157-177, May 2018. [Online]. Available: DoI: 10.1016/j.compind.2018.02.010

[3] M. C. Cooper, D. M. Lambert, and J. D. Pagh, "Supply Chain Management: More Than a New Name for Logistics," The International Journal of Logistics Management, vol. 8, no. 1, pp. 1-14, Jan 1997. [Online]. Available: DoI: 10.1108/09574099710805556

[4] D. M. Lambert and M. G. Enz, "Issues in Supply Chain Management: Progress and potential," Industrial Marketing Management, vol. 62, pp. 1-16, April 2017. [Online]. Available: DoI: $10.1016 /$ j.indmarman.2016.12.002

[5] S. H. Huan, S. K. Sheoran, and G. Wang, "A review and analysis of supply chain operations reference (SCOR) model," Supply Chain Management: An International Journal, vol. 9, no. 1, pp. 23-29, February 2004. [Online]. Available: DoI: $10.1108 / 13598540410517557$

[6] APICS, SCOR - Supply Chain Operations Reference Model, 2017.

[7] DIN Std., Reference Architecture Model Industrie 4.0 (RAMI4.0), DIN SPEC 91345, April 2016.

[8] T. Erl, Service-Oriented Architecture: Concepts, Technology, and Design. Prentice Hall, January 2005.

[9] W. Kersten, T. Blecker, and C. M. Ringle, "Artificial Intelligence and Digital Transformation in Supply Chain Management: Innovative Approaches for Supply Chains," in Proceedings of the Hamburg International Conference of Logistics (HICL) 27. Berlin: Epubli $\mathrm{GmbH}, 2019$.

[10] K. Korpela, J. Hallikas, and T. Dahlberg, "Digital Supply Chain Transformation toward Blockchain Integration," in Proceedings of the 50th Hawaii International Conference on System Sciences (2017). Hawaii International Conference on System Sciences, 2017. [Online]. Available: DoI: 10.24251/hicss.2017.506

[11] E. Isikli, S. Yanik, E. Cevikcan, and A. Ustundag, "Project Portfolio Selection for the Digital Transformation Era," in Springer Series in Advanced Manufacturing. Springer International Publishing, September 2017, pp. 105-121. [Online]. Available: DoI: 10.1007/978-3-319-57870-5_6

[12] S. E. Chang, Y.-C. Chen, and M.-F. Lu, "Supply chain reengineering using blockchain technology: A case of smart contract based tracking process," Technological Forecasting and Social Change, vol. 144, pp. 1-11, July 2019. [Online]. Available: DoI: 10.1016/j.techfore.2019.03.015

[13] A. Rajeev, R. K. Pati, S. S. Padhi, and K. Govindan, "Evolution of sustainability in supply chain management: A literature review," Journal of Cleaner Production, vol. 162, pp. 299-314, September 2017. [Online]. Available: DoI: 10.1016/j.jclepro.2017.05.026

[14] T. Hines, Supply chain strategies: Demand driven and customer focused. Routledge, 2014.

[15] G. Milovanovic, S. Milovanovic, and G. Radisavljevic, "Globalization: The key challenge of modern supply chains," Ekonomika, vol. 63, no. 1, pp. 31-40, 2017. [Online]. Available: DoI: $10.5937 /$ ekonomika1701031m

[16] D. Arunachalam, N. Kumar, and J. P. Kawalek, "Understanding big data analytics capabilities in supply chain management: Unravelling the issues, challenges and implications for practice," Transportation Research Part E: Logistics and Transportation Review, vol. 114, pp. 416-436, June 2018. [Online]. Available: Dor: 10.1016/j.tre.2017.04.001

[17] M. Christopher and J. Gattorna, "Supply chain cost management and value-based pricing," Industrial Marketing Management, vol. 34, no. 2, pp. 115-121, February 2005. [Online]. Available: DOI: $10.1016 /$ j.indmarman.2004.07.016

[18] R. Angeles, "RFID Technologies: Supply-Chain Applications and Implementation Issues," Information Systems Management, vol. 22, no. 1, pp. 51-65, December 2005. [Online]. Available: DoI: $10.1201 / 1078 / 44912.22 .1 .20051201 / 85739.7$ 
[19] S. E. Fawcett, S. L. Jones, and A. M. Fawcett, "Supply chain trust: The catalyst for collaborative innovation," Business Horizons, vol. 55, no. 2, pp. 163-178, March 2012. [Online]. Available: DoI: $10.1016 /$ j.bushor.2011.11.004

[20] M. S. Shahbaz, A. F. Chandio, M. Oad, A. Ahmed, R. Ullah, and "Stakeholders' Management Approaches in Construction Supply Chain: A New Perspective of Stakeholder's Theory," International Journal of Sustainable Construction Engineering and Technology, vol. 9, no. 2, December 2018. [Online]. Available: Dor: $10.30880 /$ ijscet.2018.09.02.002

[21] N. Pantlin, C. Wiseman, and M. Everett, "Supply chain arrangements: The ABC to GDPR compliance - A spotlight on emerging market practice in supplier contracts in light of the GDPR," Computer Law \& Security Review, vol. 34, no. 4, pp. 881-885, August 2018. [Online]. Available: Dor: 10.1016/j.clsr.2018.06.009

[22] European Parliament and Council of European Union, "Regulation (EU) 2016/679 of the European Parliament and of the Council of 27 April 2016 on the protection of natural persons with regard to the processing of personal data and on the free movement of such data, and repealing Directive 95/46/EC (General Data Protection Regulation)," 2016.

[23] D. Kozma, P. Varga, and C. Hegedus, "Supply Chain Management and Logistics 4.0 - A Study on Arrowhead Framework Integration," in 2019 8th International Conference on Industrial Technology and Management (ICITM). IEEE, March 2019. [Online]. Available: Dor: $10.1109 /$ icitm.2019.8710670

[24] S. E. Sampson and C. M. Froehle, "Foundations and Implications of a Proposed Unified Services Theory," Production and Operations Management, vol. 15, no. 2, pp. 329-343, January 2009. [Online]. Available: Dor: 10.1111/j.1937-5956.2006.tb00248.x

[25] — "Foundations and Implications of a Proposed Unified Services Theory," Production and Operations Management, vol. 15, no. 2, pp. 329-343, January 2009. [Online]. Available: DoI: $10.1111 / \mathrm{j} .1937-5956.2006 . t b 00248 . x$

[26] T. P. Stank, S. B. Keller, and P. J. Daugherty, "Supply Chain Collaboration and Logistical Service Performance," Journal of Business Logistics, vol. 22, no. 1, pp. 29-48, March 2001. [Online]. Available: Dor: 10.1002/j.2158-1592.2001.tb00158.x

[27] M. Barratt, "Understanding the meaning of collaboration in the supply chain," Supply Chain Management: An International Journal, vol. 9, no. 1, pp. 30-42, Ferbruary 2004. [Online]. Available: DoI: $10.1108 / 13598540410517566$

[28] L. Horvath, "Collaboration: the key to value creation in supply chain management," Supply Chain Management: An International Journal, vol. 6, no. 5, pp. 205-207, December 2001. [Online]. Available: DoI: $10.1108 /$ eum0000000006039

[29] Z. Cao, B. Huo, Y. Li, and X. Zhao, "The impact of organizational culture on supply chain integration: a contingency and configuration approach," Supply Chain Management: An International Journal, vol. 20, no. 1, pp. 24-41, January 2015. [Online]. Available: DoI: $10.1108 / \mathrm{scm}-11-2013-0426$

[30] D. J. Bowersox, D. J. Closs, and T. P. Stank, 21st century logistics: making supply chain integration a reality. Council of Supply Chain Management Professionals, 1999.

[31] D. Prajogo and J. Olhager, "Supply chain integration and performance: The effects of long-term relationships, information technology and sharing, and logistics integration," International Journal of Production Economics, vol. 135, no. 1, pp. 514-522, January 2012. [Online]. Available: DoI: 10.1016/j.ijpe.2011.09.001

[32] T. E. Vollmann, Manufacturing planning and control for supply chain management. McGraw-Hill Education, 2005.

[33] H. Sarimveis, P. Patrinos, C. D. Tarantilis, and C. T. Kiranoudis, "Dynamic modeling and control of supply chain systems: A review," Computers \& Operations Research, vol. 35, no. 11, pp. 3530-3561, November 2008. [Online]. Available: DoI: $10.1016 /$ j.cor.2007.01.017

[34] L. S. Dias and M. G. Ierapetritou, "From process control to supply chain management: An overview of integrated decision making strategies," Computers \& Chemical Engineering, vol. 106, pp. 826-835, November 2017. [Online]. Available: Dor: $10.1016 /$ j.compchemeng.2017.02.006
[35] D. Kozma, P. Varga, and G. Soos, "Supporting Digital Production, Product Lifecycle and Supply Chain Management in Industry 4.0 by the Arrowhead Framework - a Survey," in 2019 IEEE 17th International Conference on Industrial Informatics (INDIN). IEEE, July 2019. [Online]. Available: DoI: 10.1109Findin41052.2019.8972216

[36] R. Handfield, E. Nichols, and E. Nichols, Introduction to Supply Chain Management. Prentice Hall, 1999.

[37] J. T. Mentzer, W. DeWitt, J. S. Keebler, S. Min, N. W. Nix, C. D. Smith, and Z. G. Zacharia, "Defining Supply Chain Management," Journal of Business Logistics, vol. 22, no. 2, pp. 1-25, 2001. [Online]. Available: https://onlinelibrary.wiley.com/doi/abs/10.1002/j.2158-1592.2001. tb00001.x

[38] M. Christopher, Logistics \& supply chain management. Pearson UK, 2016.

[39] T. M. Simatupang and R. Sridharan, "The collaboration index: a measure for supply chain collaboration," International Journal of Physical Distribution \& Logistics Management, vol. 35, no. 1, pp. 44-62, January 2005. [Online]. Available: Dor: 10.1108/09600030510577421

[40] K. Goffin, F. Lemke, and M. Szwejczewski, "An exploratory study of 'close' supplier-manufacturer relationships," Journal of Operations Management, vol. 24, no. 2, pp. 189-209, July 2005. [Online]. Available: Dor: 10.1016/j.jom.2005.05.003

[41] B. Sahay, "Understanding trust in supply chain relationships," Industrial Management \& Data Systems, vol. 103, no. 8, pp. 553-563, November 2003. [Online]. Available: Dor: $10.1108 / 02635570310497602$

[42] M. Cao and Q. Zhang, Supply Chain Collaboration: Roles of Interorganizational Systems, Trust, and Collaborative Culture. Springer Science \& Business Media, 2012.

[43] Malhotra, Gosain, and Sawy, "Absorptive Capacity Configurations in Supply Chains: Gearing for Partner-Enabled Market Knowledge Creation," MIS Quarterly, vol. 29, no. 1, p. 145, 2005. [Online]. Available: Dor: $10.2307 / 25148671$

[44] Arshinder, A. Kanda, and S. Deshmukh, "Supply chain coordination: Perspectives, empirical studies and research directions," International Journal of Production Economics, vol. 115, no. 2, pp. 316-335, October 2008. [Online]. Available: Dor: 10.1016/j.ijpe.2008.05.011

[45] F. Chen, "Information Sharing and Supply Chain Coordination," in Supply Chain Management: Design, Coordination and Operation. Elsevier, 2003, pp. 341-421. [Online]. Available: Dor: 10.1016/s0927-0507/803/911007-9

[46] X. Li and Q. Wang, "Coordination mechanisms of supply chain systems," European Journal of Operational Research, vol. 179, no. 1, pp. 1-16, May 2007. [Online]. Available: DoI: $10.1016 /$ j.ejor.2006.06.023

[47] B. Christiansen, Handbook of Research on Global Supply Chain Management. IGI Global, 2015.

[48] C. Mathuramaytha, "Supply Chain Collaboration - What's an outcome?: A Theoretical Model," in 2011 International Conference on Financial Management and Economics IPEDR vol.11, Singapore, 2011.

[49] G. Disterer, ISO/IEC 27000, 27001 and 27002 for Information Security Management, 2013. [Online]. Available: Dor: $10.4236 /$ jis.2013.42011

[50] NIST and E. Aroms, NIST SP 800-100 Information Security Handbook: A Guide for Managers. Scotts Valley, CA: CreateSpace, 2012.

[51] AICPA, SOC $2^{T M}$ - SOC for Service Organizations: Trust Services Criteria, 2018.

[52] J. W. Lainhart, "COBITTM: A methodology for managing and controlling information and information technology risks and vulnerabilities," Journal of Information Systems, vol. 14, no. s-1, pp. 21-25, January 2000. [Online]. Available: DoI: $10.2308 /$ jis. 2000.14 .s-1.21

[53] L. Roalter, A. Moller, S. Diewald, and M. Kranz, "Developing Intelligent Environments: A Development Tool Chain for Creation, Testing and Simulation of Smart and Intelligent Environments," in 2011 Seventh International Conference on Intelligent Environments. IEEE, July 2011. [Online]. Available: Dor: 10.1109/ie.2011.43

[54] D. Kozma, P. Varga, and F. Larrinaga, "Dynamic Multilevel Workflow Management Concept for Industrial IoT Systems," IEEE Transactions on Automation Science and Engineering, pp. 1-13, 2020. [Online]. Available: Dor: 10.1109/tase.2020.3004313 
Supporting Digital Supply Chains by IoT

Frameworks: Collaboration, Control, Combination

[55] G. Urgese, P. Azzoni, J. van Deventer, J. Delsing, and E. Macii, "An Engineering Process model for managing a digitalised life-cycle of products in the Industry 4.0," in NOMS 2020 - 2020 IEEE/IFIP Network Operations and Management Symposium. IEEE, April 2020. [Online]. Available: Dor: 10.1109/noms47738.2020.9110365

[56] J. Delsing, Ed., IoT Automation. CRC Press, February 2017. [Online]. Available: Dor: $10.1201 / 9781315367897$

[57] C. Hegedus, P. Varga, and A. Franko, "Secure and Trusted Intercloud Communications in the Arrowhead Framework," in 2018 IEEE Industrial Cyber-Physical Systems (ICPS). IEEE, May 2018. [Online]. Available: Dor: 10.1109/icphys.2018.8390802

[58] M. Albano, L. Lino Ferreira, and J. Sousa, "Event Handler System: Publish/Subscribe communication for the Arrowhead world," in 12th IEEE World Conference on Factory Communication Systems (WFCS), 2016.

[59] O. Carlsson, D. Vera, J. Delsing, B. Ahmad, and R. Harrison, "Plant descriptions for engineering tool interoperability," in 2016 IEEE 14th International Conference on Industrial Informatics (INDIN). IEEE, July 2016. [Online]. Available: Dor: 10.1109/indin.2016.7819255

[60] H. Derhamy, J. Eliasson, J. Delsing, P. P. Pereira, and P. Varga, "Translation error handling for multi-protocol SOA systems," in 2015 IEEE 20th Conference on Emerging Technologies \& Factory Automation (ETFA). IEEE, September 2015. [Online]. Available: Dor: 10.1109/etfa.2015.7301473

[61] P. Varga, D. Kozma, and C. Hegedus, "Data-Driven Workflow Execution in Service Oriented IoT Architectures," in 2018 IEEE 23rd International Conference on Emerging Technologies and Factory Automation (ETFA). IEEE, September 2018. [Online]. Available: DOI: 10.1109/etfa.2018.8502665

[62] D. Kozma, P. Varga, and F. Larrinaga, "Data-driven Workflow Management by utilising BPMN and CPN in IIoT Systems with the Arrowhead Framework," in 2019 24th IEEE International Conference on Emerging Technologies and Factory Automation (ETFA). IEEE, September 2019. [Online]. Available: DoI: 10.1109/etfa.2019.8869501

[63] _ _ "System of Systems Lifecycle Management - A new concept based on process engineering methodologies," Journal of Intelligent Manufacturing, 2021, Accepted.

[64] G. Kulcsar, M. S. Tatara, and F. Montori, "Toolchain Modeling: Comprehensive Engineering Plans for Industry 4.0," in IECON 2020 The 46th Annual Conference of the IEEE Industrial Electronics Society. IEEE, October 2020. [Online]. Available: DOI: $10.1109 /$ iecon 43393.2020 .9254855

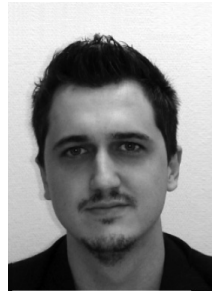

Dániel Kozma received his MSc degree in Electrical Engineering at Budapest University of Technology and Economics (BME), Hungary, in 2015. He is an experienced database software engineer with a demonstrated history of working in telecommunications. He is currently working as an Information Security Officer. In parallel, he is also a researcher as a Ph.D. student at BME within the Productive 4.0 project. His research focuses on the different areas of Industry 4.0 , such as automated production, supply chain- and lifecycle management, furthermore cyberand information security.

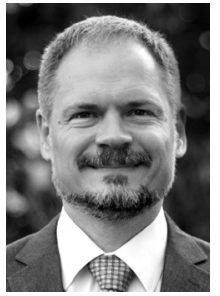

Pal Varga is currently an Associate Professor at the Budapest University of Technology and Economics, and Director at AITIA International Inc.

His main research interests include communication systems, network performance measurements, root cause analysis, fault localisation, traffic classification, end-to-end QoS and SLA issues - for which he is keen to apply hardware acceleration and artificial intelligence techniques as well. Recently he has been actively engaged with research related to CyberPhysical Systems and Industrial Internet of Things.

He has been involved in various industrial as well as European research and development projects in these topics. 